Trinity University

Digital Commons@ Trinity

Education Faculty Research

Education Department

2019

\title{
Educator Perceptions of a Schoolwide Writing Intervention Implementation: Implications for Practice
}

Heather Haynes Smith

TrinityUniversity, hhaynes@trinity.edu

Courtney Crim

TrinityUniversity, clambert@trinity.edu

Samantha Bos

Follow this and additional works at: https://digitalcommons.trinity.edu/educ_faculty

Part of the Education Commons

\section{Repository Citation}

Smith, H.H., Crim, C.L., \& Bos, S. (2019). Educator perceptions of a schoolwide writing intervention implementation: Implications for practice. Preventing School Failure, 63(1), 12-23. doi:10.1080/1045988X.2018.1456401

This Pre-Print is brought to you for free and open access by the Education Department at Digital Commons @ Trinity. It has been accepted for inclusion in Education Faculty Research by an authorized administrator of Digital Commons @ Trinity. For more information, please contact jcostanz@trinity.edu. 
Educator Perceptions of a School-wide Writing Intervention Implementation:

Implications for Practice

Heather Haynes Smith

1 Trinity Lane, Education Department, Trinity University, San Antonio, TX 78212, USA hhaynes@trinity.edu

Courtney Lambert Crim

1 Trinity Lane, Education Department, Trinity University, San Antonio, TX 78212, USA clambert@trinity.edu

Samantha Bos

8507 Chat Lane, Round Rock, TX, 78681m USA

the.samantha.bos@gmail.com 


\title{
PERCEPTIONS OF SCHOOL-WIDE WRITING INTERVENTION
}

\begin{abstract}
Students with disabilities continue to perform below peers without disabilities in writing. To address the need for improving written expression for students with learning differences, schools are implementing instructional strategies. This study investigated teacher perceptions of a fouryear, school-wide, K-12 implementation of Strategic Instruction Model (SIM) Learning Strategies addressing written expression. A survey $(n=22)$ and semi-structured interviews $(n=16)$ were administered to examine the perceptions of educators on school-wide supports to strengthen writing skills across all grades and content areas. The analysis of these data can provide insight to faculty knowledge and attitudes toward implementation of SIM as well as guidance to inform change and implementation practices in providing targeted intervention in writing to address $\mathrm{K}$ 12 goals for students with various learning differences.
\end{abstract}

Keywords: educator perceptions, intervention, learning disabilities, school-wide systems, writing 


\section{PERCEPTIONS OF SCHOOL-WIDE WRITING INTERVENTION}

Educator Perceptions of a School-wide Writing Intervention Implementation:

Implications for Practice

Students with disabilities continue to perform below peers without disabilities in writing. For example, in the 2011 National Assessment of Educational Progress (NAEP) the average scale score for writing of twelfth graders with an identified disability or 504 plan was 112 , while the scale score for students not identified with a disability was 153 (USDOE, 2011). To address the need for improving written expression for students with learning disabilities (LD), schools are implementing instructional strategies, which are methods and tools educators use to deliver content, information, and/or direction to students to facilitate student learning (Bulgren, 2006). Graham, Harris, \& Chambers (2015) recommend teaching writing skills, strategies, knowledge, and motivation as evidence-based practices (EBPs). Evidence-based programs "exist now which can be used to teach students with LD the writing strategies that they need to use through high school and into postsecondary life" (Schumaker \& Deshler, 2009). Even as many schools are introducing EBPs, there remains a struggle to implement these EBPs with fidelity to achieve the success touted in the theoretical development of these programs (Humphrey, Lendrum, Ashworth, Frearson, Buck, \& Kerr, 2016).

The purpose of this study is to understand the perceptions of educators implementing Strategic Instruction Model (SIM) Learning Strategies as an intervention to improve writing skills across all content areas in Kindergarten to twelfth grade (K-12), school-wide. The results of the survey and interviews can provide guidance to inform change and implementation practices in providing targeted intervention in writing to address K-12 goals for students with various learning differences. 


\section{PERCEPTIONS OF SCHOOL-WIDE WRITING INTERVENTION}

\section{Literature Review}

\section{The Strategic Instruction Model}

The quality of instruction has been found influential on student academic outcomes (Darling-Hammond, 2000; Haager, Klingner, \& Vaughn, 2007). SIM Learnings Strategies and Content Enhancement Routines were created and researched at the University of Kansas as part of the Institute for Research on Learning (now the Center for Research on Learning) to improve performance of at-risk students. The Content Enhancement Routines are teacher-focused to assist teachers in thinking, adapting, organizing, and presenting their content to diverse students in a manner that maximizes student learning. The Learning Strategy interventions of SIM are student-focused and assist with acquisition, organization, and expression of information (Bulgren, 2006). Further, research suggests the "best results come when strategy training is used metacognitively, with appropriate motivational and contextual support” (Hattie, Biggs, \& Purdie, 1996, p. 129).

\section{Change}

Approaching this change of implementing SIM on a campus is not a simple or quick task. In his book, Leading Change (1996), John Kotter proposes that to motivate change to happen, a sense of urgency must be initiated. School staff members must see the need for change for it to be successful. A powerful tool to demonstrate the urgent need for change is to make the staff aware of current student data. Considering existing academic data is one way to get teachers talking about how to support students who are struggling. However, schools should avoid the desire to implement many change efforts simultaneously. Skrtic (1995) provides insight into a needed shift from singular focus on the innovations/programs to concern for the whole school and their culture. Schools need to work toward long-term improvement, not a short term fix. 


\section{PERCEPTIONS OF SCHOOL-WIDE WRITING INTERVENTION}

The process of change is difficult for school leaders to enact. Many teachers are reluctant or resistant to change in schools as they may have experienced many poorly implemented initiatives in the name of producing better outcomes for students. 'Change fatigue' can occur when school reform movements or initiatives are implemented back-to-back-to-back over time (Morgan, 2001). As such, teachers are then too tired to tackle the hard work of another change in the school organization, especially when they have been involved in many hours of professional development, planning, meeting, or implementation with only minimal effect on their practices. (Kotter, 1996; Morgan, 2001). An adhocracy, with the school organization in control, should be flexible and adaptable, focusing on problem solving, teaching and collaboration (Skrtic, 1995) for implementation. Unfortunately, this is not the model often found in our top down, current school structure.

\section{Implementation}

For effective change to be ultimately useful to students, complex interventions must be implemented with fidelity in practice and sustained over time (Sailor, 2009). When skillfully delivered, fidelity ensures students will experience the critical components of the intervention. At the school level, implementation should allow for different needs in different schools, preventing a one size fits all approach. School level implementation should also focus on collaborative processes. Fullen (2007) suggests shared vision and shared meaning as critical to implementation. Implementation should consider collaborative work cultures, the inclusion of parents, and teacher collaboration (Sailor, Wolf, Choi \& Roger, 2009).

Further, Marzano (2007) suggests the responsibility for creating and maintaining culture relies on school administration. According to Bredeson (2000), principals play a large part in creating the learning environment at school as well as provide the opportunities for teachers to 


\section{PERCEPTIONS OF SCHOOL-WIDE WRITING INTERVENTION}

improve their teaching through professional development opportunities. Together, culture and professional development can have positive impact on student outcomes.

Researchers in school change believe teachers are the most integral part of comprehensive school reform (Elmore, 2007; Fullan, 2007). Although there are multiple roads to implementation, perhaps the most effective involves the mastery and continued support from teachers rather than the top-down down approach of administrative mandates (Gersten, Chard, \& Baker, 2000). Supporting teachers with quality professional development activities that are tehn reinforced within the context of their classrooms is a vital part of the change process. Having job-embedded learning opportunities with support, such as classroom coaching, will make the changes in teacher practice more effective (Knight, 2006).

In implementing a program throughout the school, there are a number of considerations that teachers and principals alike need to consider to guarantee a smooth initiation and implementation of a program that is practiced with fidelity. One of the greatest pitfalls that schools can face when implementing a rigorous EBP can be the issue of fidelity. As Deshler highlights (2005), interventions are considerably less effective when not implemented with fidelity. Leko (2015) suggests that teachers can make adaptations to programs, but only to the peripheral aspects of the program, never to the core principles that make the programs so effective in helping students learn. It is necessary for teachers as well as principals and learning experts to monitor and ensure that programs are being held to high standards of fidelity to ensure their success. Collaboration can assist in guaranteeing that programs are effectively carried out.

The science of implementation has advanced significantly in the past decade and best practices operationalize implementation frameworks (Fixsen, Naoom, Blase, Friedman, \& Wallace, 2005). In the past, schools and educators spent considerable effort designing and 


\section{PERCEPTIONS OF SCHOOL-WIDE WRITING INTERVENTION}

selecting the intervention only to then "let implementation happen." Guidance and a plan for implementation roles and drivers are needed (Fixsen, et al., 2005). Balas \& Boren (2000) found that approaches that do not adequately address or reflect research on planning in implementation were only $14 \%$ effective after about 17 years. In contrast, implementation teams relying on new knowledge regarding the stages of implementation, including planning, achieve about $80 \%$ implementation success in around 3 years (Chamberlain, 2003; Fixsen, Blase, Timbers, \& Wolf, 2001).

For sustainability to be successful, teachers must find a program to be effective; once they determine that a program is achieving the goal of helping students, teachers are more likely to continue implementation (Gersten, Chard, \& Baker, 2000). Joyce \& Showers (2002) suggest that teacher qualities that promote an aptitude for learning include: persistence, flexibility, and proactive and productive use of peers, among other traits. Teachers who are willing to accept that the implementation of a new program may initially be challenging and are prepared to use their resources, are generally able to develop the skills necessary to promote the program and student success.

Research tells us that for students with LD to close the achievement gap and write on the same level as their peers, they need intensive validated instruction (Deshler, 2005). Students with LD who do not receive explicit writing instruction write, on average, at a fourth-grade level throughout their high school career (Warner, Schumaker, Alley, \& Deshler, 1980). In addition to higher expectations in the classroom due to the inclusion of writing objectives in the Common Core (Common Core Standards Initiative, 2010), many students are also expected to provide writing samples when applying to college or when taking college entrance exams. It is therefore 


\section{PERCEPTIONS OF SCHOOL-WIDE WRITING INTERVENTION}

critical for students with LD to receive targeted, effective writing instruction to be successful both in high school and beyond.

\section{Method}

\section{Participants}

Participants in this study were classroom teachers of students K-12 at a private school for students with learning differences in the Southwestern United States. One teacher was on leave and three who do not teach academic subjects were not included in the study. Of the 26 remaining faculty, a total of 22 teachers voluntarily participated in the survey $(84.6 \%$ participation). Nine (41\%) of the 22 survey respondents were lower school teachers and 13 (59\%) were middle and/or upper school teachers. Additionally, $9(41 \%)$ had been teaching in the school less than 5 years and $13(59 \%)$ had been teaching in the school more than 5 years. Of the 22 participants who completed the survey, 16 also voluntarily participated in a semi-structured interview (61.5\%) process during their conference period or before school over a two-week period. Nine $(56 \%)$ of the 16 interview participants were lower school teachers and 7 (44\%) were middle and/or upper school teachers. Additionally, 5 (31\%) of the interview participants had been teaching in the school less than 5 years and $11(69 \%)$ had been teaching in the school more than 5 years.

The identified school began training and implementation of three SIM Learning Strategies to address improvement in written expression of students. The initial phase of implementation focused on school-wide teacher training of three SIM Learning Strategies: the Sentence Writing Strategy, the Paragraph Writing Strategy and the Theme Writing Strategy. Since initial implementation, additional SIM Learning Strategies and SIM Content Enhancement 


\section{PERCEPTIONS OF SCHOOL-WIDE WRITING INTERVENTION}

Routines (CERs) have been incorporated. This survey was administered in the fall of the fourth year of implementation.

\section{Survey Design and Procedure}

Initial creation of the SIM Writing Implementation Knowledge and Attitude Survey (WIKAS) was based on common standards for attitude surveys. The first test questions written were developed using general guidelines of simple wording, avoidance of negatively stated items, and only address one idea per question (Fowler, 1995). The items for this knowledge and attitude survey were adapted from an earlier validated scale, created by the researcher, seeking to understand another system implementation topic. It was determined by the researchers to use a Likert type scale to measure knowledge and attitude, having participants respond to wording indicating whether they "strongly agree", "agree", were "neutral", "disagree”, or "strongly disagree". In addition to these five options, researchers also provided an option that allowed respondent to indicate "Don't know or not applicable" (Fowler, 1995). WIKAS measures teacher knowledge and attitudes about the implementation of the SIM curriculum over the last four years.

The Likert and Likert type scales are the most widely used attitude scale type in the social sciences and tends to have high reliability (DeVellis, 2003). This survey has 24 items: 6 selfreported knowledge items and 18 self-reported attitudinal items. Descriptive data provided by SPSS was used to determine the internal reliability for items measuring knowledge. The analysis determined high reliability for the knowledge items, $\alpha=.805$. In an effort to keep the survey short, researchers chose not to add knowledge items to further improve internal reliability. Descriptive data provided by SPSS was also used to determine the internal reliability for items measuring attitudes. The analysis determined high reliability for all items, $\alpha=.903$. The survey 


\section{PERCEPTIONS OF SCHOOL-WIDE WRITING INTERVENTION}

knowledge and attitude questions are provided in Appendix A. Construct validity and content validity also provide evidence to support that this survey is a valid measurement tool. Construct validity is evidenced in the reference and reliance on theory to support the valid construction of knowledge and attitude surveys. Content validity is evidenced in the definition of SIM and the content of the questions aligning with the key features and creation of all SIM Learning Strategies. The research study was presented at a faculty meeting by the research team. Teachers with academic courses were invited to participate and provided a pencil and paper survey to complete. Additionally, an electronic invitation to participate in a semi-structured interview was sent to teachers with academic courses. Surveys were completed independently and returned to the researchers. Surveys collected were entered into Statistical Package for the Social Sciences (SPSS) and the research analyzed the descriptive statistics. Researchers coordinated schedules with volunteers for semi-structured interviews to be conducted before school, after school, or during lunch or conference time over a two-week period.

\section{Semi-Structured Interviews}

Participants for the semi-structured interviews were recruited during two, after school faculty meetings. Here, researchers outlined the study, provided a summary handout, and allowed teachers to sign up for interview spots. Teachers were told that participation was voluntary and the study had been designed in a way to make the responses anonymous and unidentifiable. Researchers explained that participation would include signing up for a time slot, filling out a short survey, and participating in a brief one-on-one interview, which was expected to take about 10 minutes. The researchers discussed that the information would inform practice and research on school-wide program implementation, especially for SIM. Teachers were also 


\section{PERCEPTIONS OF SCHOOL-WIDE WRITING INTERVENTION}

informed that participants would receive a catered lunch as a thank you for their contribution to the study.

Semi-structured interviews were conducted in the teachers' classrooms at the time selected. Both researchers, to establish consistency in tone and structure, conducted several of the first interviews together. In the remaining interviews, participants met with one of the two researchers. The semi-structured interview was designed to be conversational in nature (Fylan, 2005) with four guiding questions (listed below), allowing for additional follow-up questions from the researchers for clarification or elaboration.

1. What do you think is the most important factor or factors contributing to successful implementation of SIM?

2. In what areas could SIM implementation and instruction be improved?

3. What benefits for students have you observed? Elaborate.

4. Can you think of a student for whom SIM wasn't helpful or appropriate? Explain. The first two questions were designed with a programmatic implementation focus and the second two were designed to explore student impact. Interviews were recorded and coded, digital audio files were uploaded, and typed transcriptions were made of all interview recordings using Express Scribe software. For qualitative analysis, researchers used an open-coding process (Emerson, Fretz, \& Shaw, 1995). Individually, researchers read the transcriptions and identified preliminary themes for each question. Following initial review, the researchers worked collaboratively and discussed the preliminary themes, which allowed them to create, combine, or collapse the preliminary themes into a final set of themes for each question. 


\section{PERCEPTIONS OF SCHOOL-WIDE WRITING INTERVENTION}

\section{Results}

As the study explores both quantitative and qualitative data, the results are provided in these areas separately. The discussion section will highlight the overlap and relationships found in the outcomes. At the conclusion of data collection, researchers analyzed anonymous surveys from $84.6 \%$ of teachers $(n=22)$ and interview transcripts from $59.2 \%$ of teachers $(n=16)$.

\section{Survey Results}

The WIKAS was provided to all 26 classroom teachers for voluntary, anonymous participation. Surveys were completed by 22 teachers representing an $84.6 \%$ response rate. A teacher lunch incentive was provided for participating teachers once the data collection was concluded. Descriptive statistics for each items' responses are provided in Table 1 and Table 2. All items weren't completed by all participants. Questions Qe and Qk are calculated with n=21 with all other items based on the 22 completed surveys.

Teacher knowledge. Teachers' responses regarding knowledge of the SIM were generally high (Table 1) averaging above 3.5 on a 5-point scale. The statement with the lowest reported mean, SIM can be used to improve student reading outcomes, was rated between neutral and mildly agree $(M=3.33)$, by participating teachers. The second lowest knowledge statement, SIM can be used to improve student organization skills was reported as just under mildly agree $(M=3.95)$ by teachers. The question with the highest mean, I am familiar with the SIM model, was reported above agree and almost strongly agree $(M=4.6)$. The second highest knowledge statement, SIM can be used to improve writing outcomes, also scored between agree and strongly agree $(M=4.5)$. The remaining two questions, written expression can be improved using SIM and SIM is an evidence-based strategy, both scored slightly above agree with scores of $M=4.23$ and $M=4.27$, respectively. 


\section{PERCEPTIONS OF SCHOOL-WIDE WRITING INTERVENTION}

Teacher attitudes. Data outcomes for teacher attitudes demonstrate a greater range in survey responses (range $M=2.45-4.31$ ) then the knowledge focused questions. Data outcomes for the survey included information about teachers' perceptions regarding the effectiveness of SIM strategies in teaching a variety of subjects, the ease of implementation, and teacher growth as a result of implementing SIM strategies. The survey also inquired about teachers' perceptions regarding leadership roles and support of implementing SIM strategies, as well as the roles of data and technology in implementing SIM at the campus. See Table 2 for teachers' responses regarding their perceptions of SIM in the classroom.

Table 1

Mean Score for Responses on Knowledge Items of the WIKAS

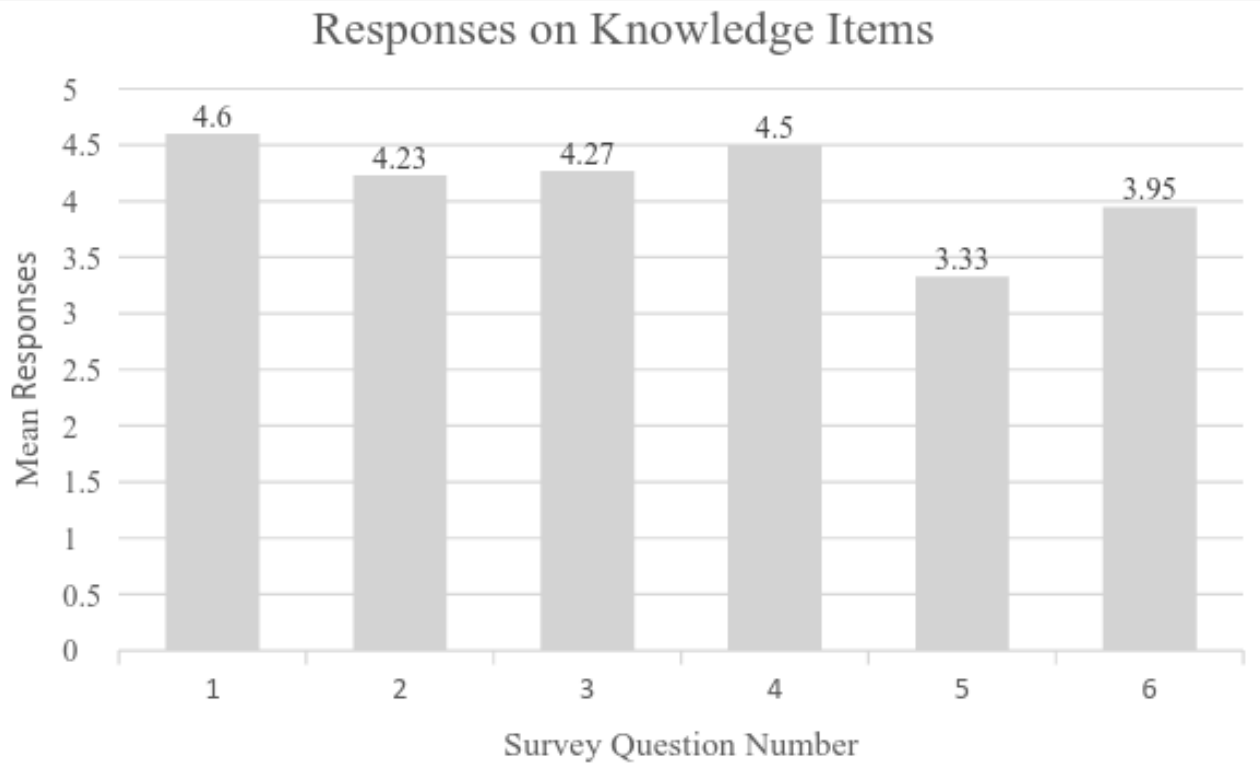

When teachers were asked about the effectiveness of SIM in improving student outcomes, there were differences in teachers' perceptions regarding SIM depending on the subject. Among the top responses was that SIM is an effective way to improve writing outcomes 


\section{PERCEPTIONS OF SCHOOL-WIDE WRITING INTERVENTION}

for students $(M=4.32)$. In contrast, teachers' responses regarding SIM's effectiveness to improve reading outcomes for students averaged only slightly above agree $(M=3.09)$. Teachers felt more strongly that SIM is an effective way to improve all academic outcomes for students $(M=3.41)$.

Among some of the lowest areas of teacher attitude involved the ease of implementation of SIM. The idea that SIM is easy for a school to implement $(M=2.97)$ as well as SIM is easy for the teacher to implement $(M=3.02)$ were close to or on the negative side of neutral $(<3.0)$. In addition, the lowest score regarding teacher attitude was that all schools should implement SIM $(M=2.45)$. In contrast, teachers' response that the school should continue to implement SIM $(M=3.95)$ was among some of the higher scores in the survey. An additional attitude rated high by participants was that implementing SIM has expanded [the teacher's] knowledge and skills regarding how to teach writing $(M=3.86)$.

There were multiple areas of highly reported attitudes in the area of school climate and implementation support. Teachers identified that they collaborate with other teachers and support professionals in implementing SIM $(M=4.27)$, received helpful information about implementation through professional development in my school or district $(M=4.22)$ and that school leaders are knowledgeable about implementing SIM $(M=3.86)$. In addition, teachers reported moderate to high attitudes regarding feeling supported in implementing SIM $(M=4.22)$ and that SIM is an important piece of a school's culture $(M=3.45)$. Despite these high remarks regarding leadership and general collaboration, the second lowest area of teacher attitude was that teachers in my school are more collaborative since we began implementing $\operatorname{SIM}(M=2.5)$. Theories for this lower score contrasted with the others in this cluster are offered in the discussion. 


\section{PERCEPTIONS OF SCHOOL-WIDE WRITING INTERVENTION}

Two clusters that held some of the lowest responses from teachers centered on teachers' attitudes towards data collection and technology. In regards to data collection, teachers' response regarding that they use the data collected as part of implementing SIM in making instructional decisions $(M=3.32)$ was slightly lower than whether they value the data collected as part of SIM $(M=3.59)$. Regarding technology, teachers' responses were slightly above neutral in regards to technology is important in implementing SIM $(M=3.2)$ but were below neutral regarding use information and resources I find on websites in planning and implementing SIM $(M=2.64)$.

Table 2 Mean Score for Responses on Attitude Items of the WIKAS

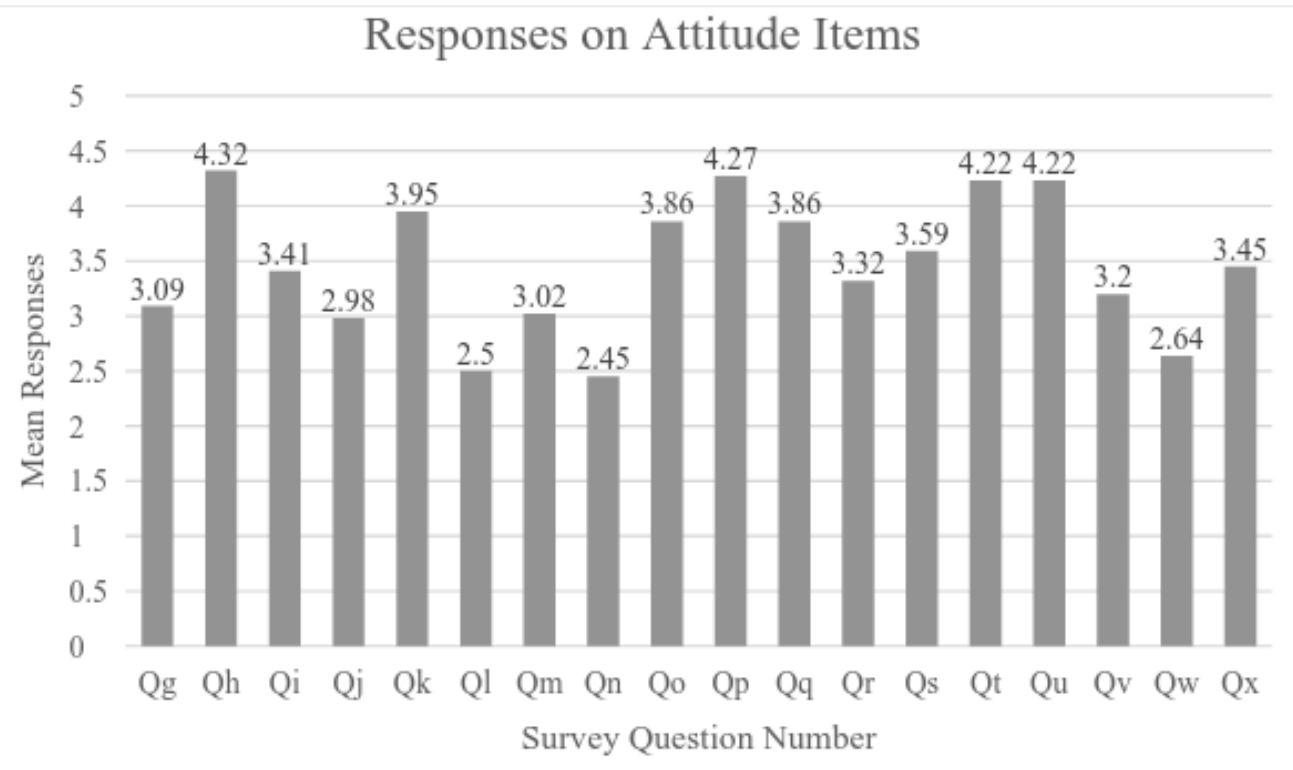

Correlations. Looking at the survey results for relationships between teachers' responses to certain questions, there were a number of correlations that arose. There were five questions that stood out as having strong correlations or a large number of correlations to other responses. The five questions included Qb: Written expression can be improved using the Strategic 


\section{PERCEPTIONS OF SCHOOL-WIDE WRITING INTERVENTION}

Instruction Model (SIM); Qk: My school should continue implementing SIM; Qr: I use the data collected as part of implementing SIM in making instructional decisions; Qs: I value the data collected as part of SIM; and Qx: SIM is an important piece of a school's culture. These results are expanded by question.

Written expression can be improved using SIM. Teachers responses regarding whether written expression can be improved using the Strategic Instruction Model was the most correlative statement, with connections to 11 separate other questions with a correlation of at least $r=0.548$ and many correlations much higher. This statement was most highly correlated to Qh: SIM is an effective way to improve writing outcomes for students ( $r=0.895)$. Teachers' responses regarding the improvement of written expression by using SIM were also moderately to highly correlated to academic improvements and teacher collaboration as seen in Qi: SIM is an effective way to improve all academic outcomes for students $(r=0.686)$ and Qp: I collaborate with other teachers and support professionals in implementing SIM (0.648).

My school should continue implementing SIM. The statement regarding how teachers felt about the future of SIM and whether my school should continue implementing SIM held correlations to nine other statements in a variety of areas regarding teacher knowledge and attitudes at or above a correlation of $r=0.552$. This statement most highly correlated with whether the school should continue the use of SIM Qs: I value the data collected as part of SIM $(r=0.817)$. Teachers' responses to whether the school should continue to implement SIM held strong correlations with five of the six statements regarding teacher knowledge of SIM including: Qb: Written expression can be improved using the Strategic Instruction Model (SIM) ( $r=0.655)$; Qc: SIM is an evidence-based strategy $(r=0.589)$; Qd: SIM can be used to improve student writing outcomes ( $r=0.581$ ); Qe: SIM can be used to improve student reading outcomes 


\section{PERCEPTIONS OF SCHOOL-WIDE WRITING INTERVENTION}

$(r=0.580)$; and Qf: SIM can be used to improve student organization skills $(r=0.600)$. Finally, teachers' responses to the continued use of SIM showed a correlation to Qp: I collaborate with other teachers and support professionals in implementing SIM $(r=0.582)$.

\section{I use the data collected as part of implementing SIM in making instructional decisions.}

This statement regarding using data collection correlates with 7 other statements, each with a correlation of $r=0.554$ or higher. Besides the correlations mentioned above, this statement showed a strong correlation to the other data related question, Qs: SIM is an effective way to improve all academic outcomes for students $(r=0.796)$. This statement of data collection also showed strong correlations to Qh: SIM is an effective way to improve writing outcomes for students $(r=0.732)$ and Qp: I collaborate with other teachers and support professionals in implementing SIM $(r=0.696)$.

I value the data collected as part of SIM. This statement, looking at whether teachers value data more than if they use the data, correlated with 10 other statements, many of them similar to the correlations in the preceding question. Similar to Qr regarding data use, the statement regarding valuing data had moderate correlations with Qf: SIM can be used to improve student organization skills ( $r=0.662$ and 0.671 , use and value respectively) and Qg: SIM is an effective way to improve reading outcomes for students ( $r=0.555$ and 0.55 , use and value respectively). Unlike the previous statement of data collection, the statement regarding valuing data did correlate moderately with Qc: SIM is an evidence-based strategy $(r=0.612)$ and Qm: SIM is easy for a teacher to implement $(r=0.548)$.

SIM is an important piece of a school's culture. Finally, this statement regarding school culture was found to have a correlation of 0.548 or higher with eight other statements. This statement had the highest correlation with Qu: I am supported in implementing SIM $(r=0.848)$. 


\section{PERCEPTIONS OF SCHOOL-WIDE WRITING INTERVENTION}

The question of a school's culture was also highly correlative with Qm: SIM is easy for a teacher to implement $(r=0.722)$ and Qq: My school leaders are knowledgeable about implementing SIM $(r=0.799)$. The statement of school culture had moderate to high correlations with the two questions concerning data: Qr: I use the data collected as part of implementing SIM in making instructional decisions ( $r=0.582)$, and Qs: I value the data collected as part of SIM ( $r=0.623)$.

\section{Interview Results}

When analyzing the qualitative data, researchers used interview transcripts from the 16 teachers who participated in this part of the study (59.2\%). While educators identified many important factors contributing to the successful implementation of SIM for improving written expression, researchers found they clustered under three overarching themes: vision, plan, and fidelity. Diagram 1 shows the overlap of key themes that emerged from the interview data.

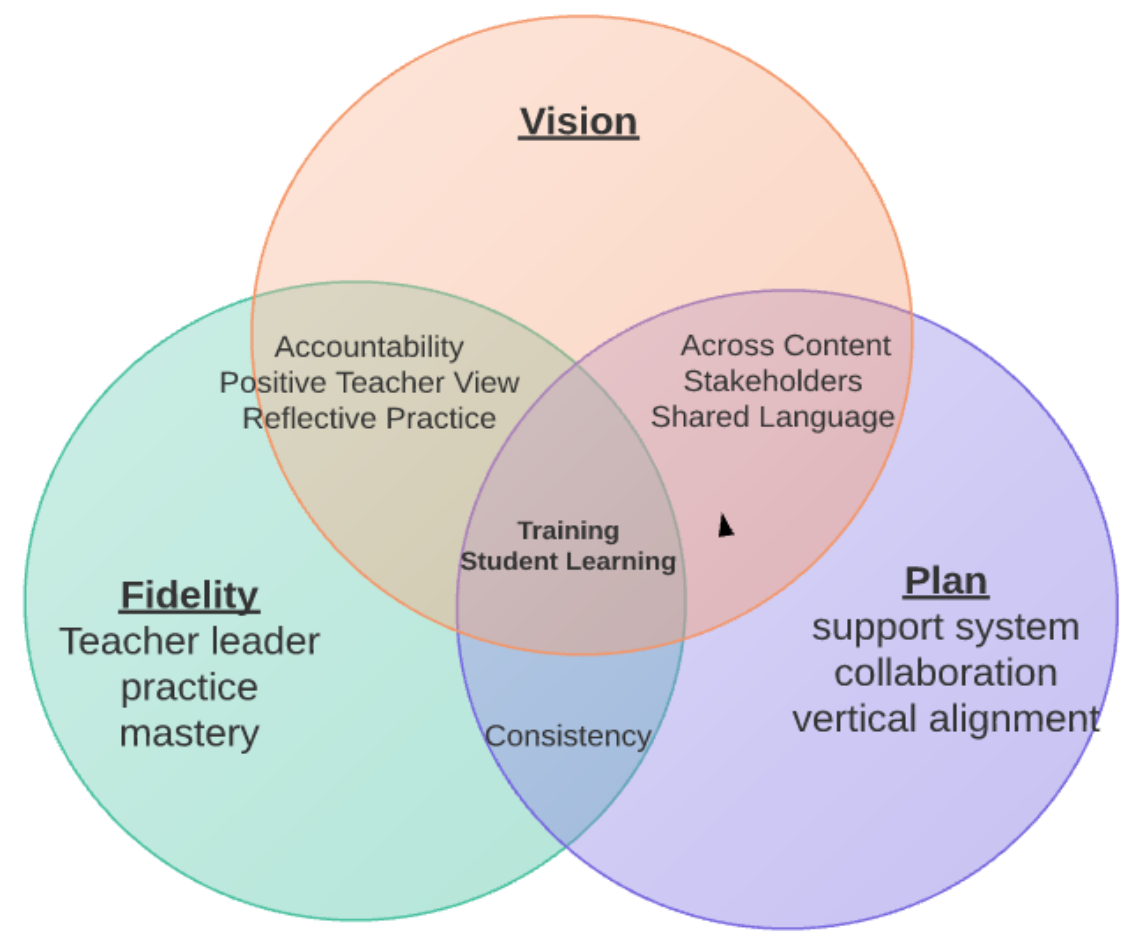

Figure 1. Overarching themes identified in the interview analysis. 


\section{PERCEPTIONS OF SCHOOL-WIDE WRITING INTERVENTION}

\section{Vision}

In 14 of the 16 interviews, teachers responded at least once with answers that reflected an emphasis on the shared vision necessary for SIM Learning Strategies to be successful. Five teachers spoke directly about the need for the school to have a shared vision as the most important element for SIM to be implemented successfully. One teacher said, "I think the stakeholders involved need to have a clear vision of what SIM is, they need to have a clear understanding of what learning strategies and CER are, and have a significant number of teachers buy in to, not only the effectiveness, but the need for the program."

Nine teachers spoke about the evidence of student learning because of the implementation of SIM Learning Strategies and CER. Of these nine, six of these teachers spoke directly to the benefits seen in the students' writing or their willingness to write after having been taught SIM Learning Strategies. Most teachers qualified their statements of support to note that the Learning Strategies worked better for some students. One teacher said, "I do see our writing scores do improve the longer the kids are with it - if the kids can buy into [the Learning Strategies]." Another teacher spoke in similar veins of the strategies being helpful for certain students: "I've seen some students get past their fear in writing. Not all of them, but some of them now - they are given some strategies, they are given little forms...- that kind of takes the fear out of the writing."

\section{Fidelity}

All 16 teachers who were interviewed spoke about some aspect of fidelity as either a critical piece of successful implementation of SIM or as a struggle that the campus was facing, preventing students from reaching their potential. Two teachers spoke specifically about the need for teachers to teach the strategies with fidelity, or "integrity" as one teacher said. When asked 


\section{PERCEPTIONS OF SCHOOL-WIDE WRITING INTERVENTION}

what was necessary for the program to be successful, one teacher spoke of the need of administration to ensure that "teachers need to be held accountable for implementing the strategies and routines with fidelity and teachers also need to hold each other accountable."

Nine teachers, including the two already mentioned, talked about aspects of the program that fell solely under the theme of fidelity. Of those nine, three teachers talked about mastery, three teachers talked about teacher leaders on campus, and three teachers talked about the role of practice, with some teachers talking about more than one topic. Perhaps more striking, 13 of the teachers talked about the need for consistency in ensuring a successful implementation of the program. Many teachers spoke to the benefits of having one program run throughout the K-12 school. As one teacher put it, "I think just the fact that we're starting in Lower School and moving it up through - that's what's going to really (help) the success." Three teachers voiced frustration when they felt that not all teachers were being consistent in teaching the writing strategies. One teacher voiced concern that when some teachers are not teaching the strategies, "then that makes one person look like the bad guy because they are doing it all."

\section{Plan}

Similar to the theme of fidelity, all 16 teachers who were interviewed spoke about some topic related to the plan and structures necessary to implement SIM successfully. No teacher used specific vocabulary of the word "plan," but 13 teachers touched on the themes of either support systems, collaboration, vertical alignment, or a combination of those three. Seven teachers talked about support systems necessary for implementation of SIM. Of the seven, one teacher had neutral comments to make about the need for support, two teachers spoke only positively about the support systems in place, three teachers had positive views of some support systems in place but felt that more could be done, and one teacher only had suggestions for 


\section{PERCEPTIONS OF SCHOOL-WIDE WRITING INTERVENTION}

improvements to the support systems at the school. For example, one teacher suggested:

"Instruction could be improved through greater support of teachers who really don't necessarily get a whole lot from the 'sit and get' trainings that SIM can be." Another teacher, who held positive views of the peer supports in place, suggested a greater need for "definitely more walkthroughs," and "instructional support leaders coming in, watching part of a lesson, planning part of a lesson with you, even saying, "what are you teaching?"'

Five of the teachers responded in the interviews about the collaboration in place or lacking at the school. Two teachers spoke highly of the collaboration in place at the school and noted that it was "easy to talk among each other." The other three teachers suggested a need for more systematic communication and collaboration among teachers. One teacher, when asked about the current collaboration responded, "it's more informal, and it's successful, but I think planned, formal collaboration would be helpful."

As noted above, 13 teachers addressed the theme of consistency, and three of these teachers talked specifically about vertical alignment in their interviews. One teacher spoke about the strength of the program rooted in its systematic alignment: "I just think it is critical for things to be sequential and build on one another." The other two teachers offered suggestions for greater vertical alignment to facilitate shared expectations for students and communication between teachers.

\section{Discussion}

Understanding implementation of SIM to improve writing for K-12 students will inform systematic use of EBPs, school-wide or in the classroom, with students with learning differences. This sentiment was supported by the data obtained in this study. Many of the themes identified in 


\section{PERCEPTIONS OF SCHOOL-WIDE WRITING INTERVENTION}

implementation and change literature (Durlak \& Dupre, 2008; Fixsen, Naoom, Blase', Friedman, $\&$ Wallace, 2005) are mirrored in the outcomes of this study.

One theme evident in the study outcomes is the importance of supporting shared vision and goals for an initiative. Strong areas of knowledge of the EBP correlated to strong attitudes for the program at the classroom level as well as positive attitudes for school-wide implementation. Participants rated the value of SIM for writing development greater than that of reading and organizational outcomes. This knowledge base was supported in the attitude responses as participants recognized that their own knowledge and skill for teaching writing improved. Additionally, the writing outcomes for students were improved through the SIM program. As Fullen (2007) suggests, shared vision and shared meaning are critical to implementation. The original purpose for the school-wide implementation of SIM was framed around the need for writing development, so this area, which received the longest and most intense focus, reflects the highest area of teachers' knowledge and attitudes regarding the program. These outcomes support Fullen's work that extended shared vision and meaning will impact implementation.

As noted earlier in the paper, school level implementation should focus on collaborative processes and should consider collaborative work cultures. Collaborative practice was an interesting area in the survey outcomes. Participants indicated that they are not more collaborative since beginning SIM implementation $(M=2.5)$, but they felt that they collaborated with other teachers and support professionals when implementing SIM $(M=4.27)$. This is a large discrepancy and the researchers interpret this as indication that there was already a stronger sense of collaboration before implementation began. The presence of a strong sense of community and collaboration aid in the sustainability of a program (Adelman \& Taylor, 2003). This outcome 


\section{PERCEPTIONS OF SCHOOL-WIDE WRITING INTERVENTION}

reinforces the importance of bringing a school-wide implementation to a healthy campus where collaboration is already fostered.

Another theme identified is that a powerful tool to demonstrate the urgent need for change is to make the staff aware of current student data. Teachers at the school have learned, through professional development, to track student progress and gain the understanding that student outcomes are improved in a range of content areas. This awareness and value of student data $(M=3.59)$ is reflected in the responses as participants recognize the value of SIM for student improvements as well as the positive response that SIM should continue at their school $(M=3.95)$. The correlation between valuing data also correlated heavily with recognition that SIM can be a powerful tool to help students improve their learning outcomes as well as teachers collaborating with colleagues. Looking at the specific correlations in the survey results, nine teachers responded that they mildly or strongly agreed with both statements regarding using and valuing data; eight of the teachers also responded that they mildly or strongly agreed that SIM should continue at the school (one teacher did not answer this question). Of these same nine teachers who used and valued data, seven strongly agreed that they collaborated with their peers (one mildly agreed, and one was neutral). One of these teachers summed up perhaps the success that can take place when collaboration and data are combined: "I think the benefits are powerful in that when we do collaborate, when the teachers and the staff do collaborate with each other, we are more successful at embracing the child's strengths and building up whatever deficits there are because we have identified the deficits." While the value of student data was an indicator of change implementation, the use of this data in making instructional decisions was not as high $(M=3.32)$. This may be an area for the school to intensify their teacher training. 


\section{PERCEPTIONS OF SCHOOL-WIDE WRITING INTERVENTION}

'Change fatigue', the outcome when school reform movements or initiatives are implemented back to back to back over time, was identified in the literature as something to avoid with effective change implementation (Morgan, 2001). The consistent and systematic introduction and gradual build of strategies seems to have fostered positive attitudes for SIM implementation, avoiding the limitation of "change fatigue" in this 4-year process. Four years after the introduction of SIM Learning Strategies for written expression, teachers' responses indicate that they agree that the school should continue to implement SIM $(M=3.95)$. These responses suggest that teachers are not experiencing "change fatigue". The researchers attribute this success to the culture present at the school, reflected in low teacher and administrative turnover, the initial planning in the school-wide approach, responses that reflect a commitment to professional development, and the continued use of data to help support the students learn.

A final theme that is a vital part of the change process is supporting teachers with quality professional development activities that are reinforced within the context of their classrooms. The fact that teachers saw that their school leaders were knowledgeable about implementing SIM $(M=3.86)$ and that SIM is an important part of the school culture $(M=3.45)$, reflects the idea that SIM is truly supported and used in many aspects of the curriculum and instruction of the school. The highest areas reported indicate that teachers received helpful information about implementing SIM $(M=4.22)$ and that they felt supported in this implementation process $(M=4.22)$. These attitudes suggest that teachers are indeed receiving valuable professional development and that their practice in the classroom includes embedded learning opportunities that support the school-wide implementation of SIM. This support will make the changes in teacher practice more effective. 


\section{PERCEPTIONS OF SCHOOL-WIDE WRITING INTERVENTION}

In conducting this study, there are limitations to the extent that information can be generalized. A lack of student data tied to results of surveys and interview data hinder the possibility of analyzing the effect teachers' opinions have upon their students' success. Perhaps the greatest limitation of this study is that it relies heavily upon self-reporting on behalf of the teachers. Observations were not feasible for the researchers to conduct at this time, but direct insights into teachers' implementation and fidelity of practice in relation to their answers would also provide interesting insight into larger implications for both the individual school as well as implementation practices in general.

When analyzing the outcomes of the teachers' knowledge and attitudes, there are definitely some clear links to effective change implementation happening. Future research will involve looking deeper into the areas that were not as positively recognized by participants. The knowledge level beyond writing content (see Humphrey, Barlow, \& Lendrum, 2017), the use of data in making instructional decisions (see Wohlstetter, Datnow, \& Park, 2008), or the possibilities of using technology may indicate areas for targeted professional development (see Montgomery \& Marks, 2006). Evaluating the effectiveness of focused professional development could be a very useful line of inquiry for the school's own growth, as well as the utilization of system wide implementation.

\section{References}

Adelman, H. S., \& Taylor, L. (2003). On sustainability of project innovations as systemic change. Journal of Educational and Psychological Consultation, 14(1), 1-25.

Balas, E. A., \& Boren, S. A. (2000). Managing clinical knowledge for health care 


\section{PERCEPTIONS OF SCHOOL-WIDE WRITING INTERVENTION}

improvement. In J. Bemmel (Ed.), Yearbook of medical informatics: Patient-centered systems. (pp. 65-70). Stuttgart, Germany: Schattauer Verlagsgesellschaft.

Bredeson, P. (2000) The school principal's role in teacher professional development. Journal of In-Service Education, 26(2), 385-401.

Bulgren, J. A. (2006). Integrated content enhancement routines: Responding to the needs of adolescents with disabilities in rigorous inclusive secondary content classes. Teaching Exceptional Children, 38(6), 54-48.

Chamberlain, P. (2003). The Oregon multidimensional treatment foster care model: Features, outcomes, and progress in dissemination. Cognitive and Behavioral Practice, 10(4), 303312.

Darling-Hammond, L. (2000). Teacher quality and student achievement: A review of state policy evidence. Education Policy Analysis Archives, 8(1), 1-44.

Darling-Hammond, L., \& Bransford, J. (Eds.). (2007). Preparing teachers for a changing world: What teachers should learn and be able to do. San Francisco, CA: John Wiley \& Sons.

Deshler, D. D. (2005). Adolescents with learning disabilities: Unique challenges and reasons for hope. Learning Disability Quarterly, 28(2), 122-124.

DeVellis, R. F. (2003). Scale development: Theory and applications. (2nd ed). Thousand Oaks, CA: Sage.

Durlak, J. A., \& Dupre, E. P. (2008). Implementation matters: A review of research on the influence of implementation on program outcomes and the factors affecting implementation. American Journal of Community Psychology, 41(3-4), 327-350.

Elmore, R. F. (2007). School reform form the inside out. Cambridge: Harvard Education Press.

Emerson, R. M., Fretz, R. I., \& Shaw, L. L. (1995). Writing ethnographic fieldnotes. Chicago, 


\section{PERCEPTIONS OF SCHOOL-WIDE WRITING INTERVENTION}

IL: The University of Chicago Press.

Fixsen, D. L., Blase, K. A., Timbers, G. D., \& Wolf, M. M. (2001). In search of program implementation: 792 replications of the Teaching-Family Model. In G. A. Bernfield, D. P. Farrington, \& A. W. Lescheid (Eds.), Offender rehabilitation in practice: Implementing and evaluating effective programs, (pp. 149-166). London, England: Wiley.

Fixsen, D. L., Naoom, S. F., Blase', K. A., Friedman, R. M., \& Wallace, F. (2005). Implementation research: A synthesis of the literature. Tampa, FL: University of South Florida.

Fowler, F. J. (1995). Improving survey questions: Design and evaluation. Thousand Oaks, CA: Sage.

Fullan, M. (2007). The new meaning of educational change. Teachers College Press: New York, NY.

Fylan, F. (2005). Semi structured interviewing. In J. Miles \& P. Gilbert (Eds.), A handbook of research methods for clinical and health psychology, (pp. 65-78). Oxford: Oxford University Press.

Gersten, R., Chard, D., \& Baker, S. (2000). Factors enhancing sustained use of research-based instructional practices. Journal of Learning Disabilities, 33(5), 445-457.

Graham, S. Harris, K. \& Chambers, A. (2015). Evidence-based practice and writing instruction: A review of reviews. In C. MacArthur, S. Graham, \& J. Fitzgerald (Eds.), Handbook of Writing Research (Volume 2), (pp. 211-266). New York, NY: Guilford.

Haager, D. E., Klingner, J. E., \& Vaughn, S. E. (2007). Evidence-based reading practices for response to intervention. Baltimore, MD: Brookes Publishing. 


\section{PERCEPTIONS OF SCHOOL-WIDE WRITING INTERVENTION}

Hattie, J., Biggs, J., \& Purdie, N. (1996). Effects of learning skills intervention of student learning: A meta-analysis. Review of Educational Research, 66(2), 99-136.

Humphrey, N., Barlow, A., \& Lendrum, A. (2017). Quality Matters: Implementation Moderates Student Outcomes in the PATHS Curriculum. Prevention Science, 19(2), 197-208.

Humphrey, N., Lendrum, A., Ashworth, E., Frearson, K., Buck, R., \& Kerr, K. (2016). Implementation and process evaluation (IPE) for interventions in education settings: A synthesis of the literature. London, England: Education Endowment Foundation.

IBM Corporation (2013). IBM SPSS Statistics for Windows, Version 22.0. Armonk, NY: IBM Corp.

Joyce, B., \& Showers, B. (2002). Student Achievement through Staff Development (3rd ed.). Alexandria, VA: Association for Supervision and Curriculum Development.

Knight, J. (2006). Instructional coaching: Eight factors for realizing better classroom teaching through support, feedback and intensive, individualized professional learning. The School Administrator, 63(4), 36-40.

Kotter, J. (1996). Leading change. Boston, MA: Harvard Business School Press.

Leko, M. M. (2015). To adapt or to not adapt: navigating an implementation conundrum. Teaching Exceptional Children, 48(2), 80-85.

Marzano, R. J. (2007). The art and science of teaching: A comprehensive framework for effective instruction. Alexandria, VA: ASCD

Montgomery, D. J., \& Marks, L. J. (2006). Using Technology to Build Independence in Writing for Students with Disabilities. Preventing School Failure, 50(3), 33-38.

Morgan, N. (2001) How to overcome “change fatigue.” Harvard Management Update, 6(7), 1-3. National Governors Association Center for Best Practices, \& Council of Chief State School 


\section{PERCEPTIONS OF SCHOOL-WIDE WRITING INTERVENTION}

Officers. (2010). Common core state standards for English language arts. Retrieved from http://www.corestandards.org/ELA-Literacy

Sailor, W. (2009). Making RTI work. San Francisco, CA: Jossey-Bass.

Sailor, W., Wolf, N., Choi, J. H., \& Roger, B. (2009a). Sustaining positive behavior support in a context of comprehensive school reform. In W. Sailor, G. Dunlap, G. Sugai, \& R. Horner (Eds.), Handbook of positive behavior support (pp. 3-16). New York: Springer.

Schumaker, J. B. (2003). The theme writing strategy: Instructor's manual. Lawrence, KS: Edge Enterprises, Inc.

Schumaker, J. \& Deshler, D. (2009). Adolescents with learning disabilities as writers: Are we selling them short? Learning Disabilities Research \& Practice, 24(2), 81-92.

Schumaker, J. B., \& Lyerla, K. D. (1991). The paragraph writing strategy: Instructor's manual. Lawrence, KS: University of Kansas.

Schumaker, J., \& Sheldon, J. (1985). Proficiency in the Sentence Writing Strategy. Lawrence, KA: Edge Enterprises, INC. KUCRL Paragraph Writing Strategy

Skrtic, T. M. (1995). Special education and student disability as organizational pathologies: Toward a metatheory of school organization and change. In T. M. Skrtic (Ed.), Disability and democracy: Reconstructing (special) education for postmodernity (pp. 190-232). New York: Teachers College Press.

Warner, M. M., Schumaker, J. B., Alley, G. R., \& Deshler, D. D. (1980). Learning disabled adolescents in the public schools: Are they different from other low achievers?. Exceptional Education Quarterly, 1(2), 27-36.

Wasburn-Moses, L. (2006). Obstacles to Program Effectiveness in Secondary Special Education. Preventing School Failure, 50(3), 21-30. 


\section{PERCEPTIONS OF SCHOOL-WIDE WRITING INTERVENTION}

Wohlstetter, P., Datnow, A., Park, V. (2008). Creating a system for data-driven decision-making: applying the principal-agent framework. School Effectiveness and School Improvement, 19(3). 239-259

U.S. Department of Education. (2011). National Assessment of Educational Progress (NAEP) Writing Assessment. Retrieved from https://nces.ed.gov/nationsreportcard/writing 
Appendix A

SIM Writing Implementation Knowledge and Attitude Survey (WIKAS)

\begin{tabular}{|c|c|c|c|c|c|}
\hline 1 & 2 & 3 & 4 & 5 & DK \\
\hline Strongly Disagree & Mildly Disagree & Neutral & Mildly Agree & Strongly Agree & Don't know or not applicable \\
\hline
\end{tabular}

\begin{tabular}{|c|l|c|c|c|c|c|c|}
\hline a. & I am familiar with the Strategic Instruction Model (SIM). & 1 & 2 & 3 & 4 & 5 & DK \\
\hline b. & $\begin{array}{l}\text { Written expression can be improved using the Strategic } \\
\text { Instruction Model (SIM) }\end{array}$ & 1 & 2 & 3 & 4 & 5 & DK \\
\hline c. & SIM is an evidence-based strategy. & 1 & 2 & 3 & 4 & 5 & DK \\
\hline d. & SIM can be used to improve student writing outcomes. & 1 & 2 & 3 & 4 & 5 & DK \\
\hline e. & SIM can be used to improve student reading outcomes. & 1 & 2 & 3 & 4 & 5 & DK \\
\hline f. & SIM can be used to improve student organization skills. & 1 & 2 & 3 & 4 & 5 & DK \\
\hline
\end{tabular}

\begin{tabular}{|c|c|c|c|c|c|c|c|}
\hline g. & $\begin{array}{l}\text { SIM is an effective way to improve reading outcomes for } \\
\text { students. }\end{array}$ & 1 & 2 & 3 & 4 & 5 & DK \\
\hline h. & $\begin{array}{l}\text { SIM is an effective way to improve writing outcomes for } \\
\text { students. }\end{array}$ & 1 & 2 & 3 & 4 & 5 & DK \\
\hline i. & $\begin{array}{l}\text { SIM is an effective way to improve all academic outcomes for } \\
\text { students. }\end{array}$ & 1 & 2 & 3 & 4 & 5 & DK \\
\hline j. & SIM is easy for a school to implement. & 1 & 2 & 3 & 4 & 5 & DK \\
\hline $\mathrm{k}$. & My school should continue implementing SIM. & 1 & 2 & 3 & 4 & 5 & DK \\
\hline 1. & $\begin{array}{l}\text { Teachers in my school are more collaborative since we began } \\
\text { implementing SIM. }\end{array}$ & 1 & 2 & 3 & 4 & 5 & DK \\
\hline $\mathrm{m}$. & SIM is easy for a teacher to implement. & 1 & 2 & 3 & 4 & 5 & DK \\
\hline $\mathrm{n}$. & All schools should implement SIM. & 1 & 2 & 3 & 4 & 5 & DK \\
\hline 0. & $\begin{array}{l}\text { Implementing SIM has expanded my knowledge and skills } \\
\text { regarding how to teach writing. }\end{array}$ & 1 & 2 & 3 & 4 & 5 & DK \\
\hline p. & $\begin{array}{l}\text { I collaborate with other teachers and support professionals in } \\
\text { implementing SIM. }\end{array}$ & 1 & 2 & 3 & 4 & 5 & DK \\
\hline
\end{tabular}

\begin{tabular}{|l|l|l|l|l|l|l|l|}
\hline q. & $\begin{array}{l}\text { My school leaders are knowledgeable about implementing } \\
\text { SIM. }\end{array}$ & 1 & 2 & 3 & 4 & 5 & DK \\
\hline r. & $\begin{array}{l}\text { I use the data collected as part of implementing SIM in making } \\
\text { instructional decisions. }\end{array}$ & 1 & 2 & 3 & 4 & 5 & DK \\
\hline s. & I value the data collected as part of SIM. & 1 & 2 & 3 & 4 & 5 & DK \\
\hline t. & $\begin{array}{l}\text { I received helpful information about implementing SIM through } \\
\text { professional development in my school or district. }\end{array}$ & 1 & 2 & 3 & 4 & 5 & DK \\
\hline u. & I am supported in implementing SIM. & 1 & 2 & 3 & 4 & 5 & DK \\
\hline v. & Technology is important in implementing SIM. & 1 & 2 & 3 & 4 & 5 & DK \\
\hline w. & $\begin{array}{l}\text { I use information and resources I find on websites in planning } \\
\text { and implementing SIM. }\end{array}$ & 1 & 2 & 3 & 4 & 5 & DK \\
\hline x. & SIM is an important piece of a school's culture. & 1 & 2 & 3 & 4 & 5 & DK \\
\hline
\end{tabular}




\section{Author Notes}

Heather Haynes Smith is an assistant professor at Trinity University. Her school level research focuses on instructional and systems approaches to support students with learning disabilities. She also studies teacher preparation for working with students with exceptionalities and inclusion.

Courtney Lambert Crim is an associate professor at Trinity University. She assists in leading the secondary education program and research interests the use of differentiation to support diverse learners.

Samantha Bos is a doctoral student at The University of Texas. She was previously an upper elementary teacher for students with learning differences. She currently researches word problems and language use for elementary students with learning disabilities in math. 